\title{
Distractor effects during processing of words under load
}

\author{
Muriele Brand-D'Abrescia \\ University College London, London, England \\ and Université de Provence, Aix en Provence, France \\ AND \\ Nilli LaVIE \\ University College London, London, England
}

\begin{abstract}
The perceptual load model of attention (Lavie, 1995) suggests that processing of irrelevant distractors depends on the extent to which a relevant task engages full perceptual capacity. Word recognition models suggest that letter perception is facilitated in words relative to nonwords. These models led us to hypothesize that increasing the number of letters would increase perceptual load more for nonwords than for words, and thus would be more likely to exhaust capacity and eliminate distractor processing for nonwords than for words. In support of this hypothesis, we found that increasing the number of search letters increases RTs more for nonwords than for words and only reduces distractor interference for nonwords. Thus, although readers process words more efficiently than nonwords, they also become more prone to distraction when processing words.
\end{abstract}

Irrelevant distractors often interfere with task performance despite the attempt to ignore them. Attention research has investigated the conditions under which such distraction by irrelevant stimuli can be prevented. One important determinant of this is the level of perceptual load in the target processing. The role of perceptual load in selective attention has been elaborated within perceptual load theory (Lavie, 1995; Lavie \& Tsal, 1994), which suggests that although perception has capacity limits, processing of all stimuli within perceptual capacity is mandatory. Distractor perception can thus be prevented when the relevant-task processing involves sufficiently high load to engage full perceptual capacity, but when the relevant processing involves only low perceptual load, spare capacity from the relevant processing "spills over" to the perception of an irrelevant distractor.

Evidence for this theory has come from many demonstrations that whereas interference by irrelevant distractors is typically found in conditions of low perceptual load in task-relevant processing, distractor interference is eliminated in conditions of high load that exhaust full capacity in the task-relevant processing (e.g., with a greater number of items requiring identification or a greater complexity of the perceptual task; see Lavie, 2005, for a review).

For example, in line with the prevalent estimate of five items for attentional capacity limits (Fischer, 1982; Pylyshyn, Burkell, Fisher, \& Sears, 1994; Yantis \& Jones, 1991), perceptual load studies using search tasks have shown that irrelevant distractors (e.g., presented outside of the search array) nevertheless produce interference effects as long as the search task involves up to five items, and that distractor interference is eliminated when the number of search items demands or exceeds full capacity (e.g., with six or more search items; Lavie \& Cox, 1997; Lavie \& Fox, 2000).

Many of these search studies have used letter stimuli, but these were meaningless in the sense that they did not form words. What are the implications for selective attention of presenting the letters within words? The word recognition literature suggests that letter perception within words (as compared with nonwords or alone) is facilitated because of top-down effects produced by either whole-word representations (e.g., McCelland \& Rumelhart, 1981) or intermediate levels, such as graphemes or syllables (Healy, 1994; LaBerge \& Samuels, 1974). The facilitation in letter perception in words has interesting implications for selective attention when conceived within perceptual load framework: Because of the top-down facilitation, letter perception within words should impose less perceptual load than letter perception within nonwords. There should thus be cases in which the same number of letters (e.g., six or more) would be sufficient to exhaust full attentional capacity when the letters do not form a word, but would leave spare capacity when the letters do form a word. Because in load theory any spare capacity, left over from relevant processing, involuntarily spills over to irrelevant processing, in such cases greater distractor processing is predicted for letters within words than within nonwords.

To test these predictions, we used a task similar to that used in Lavie (1995), but varied whether the task let-

M. Brand-D’Abrescia, muriele.brand@Ipl.univ-aix.fr 
ters formed a word or a nonword. Subjects were asked to search for the target letter "S" or " $L$ " in a central letter string that formed either a word or a nonword, and to ignore an irrelevant distractor letter presented above or below the letter string. The distractor letter could either be incompatible (e.g., distractor "L" for target "S") or compatible (distractor "S" for target "S") with the target response, and distractor compatibility effects served as an index for the distractor processing.

In order to assess the effects of word recognition on perceptual load (and hence on distractibility), we also varied the number of letters in the letter strings. Each string could be either three or eight letters long. On the basis of previous research (e.g., Lavie \& Cox, 1997), we expected that the three-letter strings would form a condition of low perceptual load in both the word and nonword conditions, since three letters is well below the five-item estimate of capacity limits. We therefore predicted that with threeletter strings participants would be equally likely to process the irrelevant distractor (due to a spill-over of spare attentional capacity) in both the word and nonword conditions. Our interesting prediction concerned the eight-letter strings. The eight letters in the nonword condition should clearly consume (indeed exceed) full attentional capacity, leaving none for distractor processing. But the reduction in perceptual load due to the facilitation in letter perception in words (established in the word recognition literature) should mean that processing the eight-letter words would leave spare capacity, and this would spill over to the distractor processing. We thus predicted that eight-letter words would be more prone to distractor interference than would eight-letter nonwords.

\section{EXPERIMENT 1}

\section{Method}

Participants. Twenty-four native English speakers from UCL, and 24 native French speakers from the Université de Provence participated in exchange for payment or course credit. All had a normal or corrected-to-normal vision.

Stimuli and Apparatus. The experiment was conducted on an Apple computer using PsyScope software. Participants were seated $60 \mathrm{~cm}$ from the computer screen. All letters were presented in white on a black background. The letters in the central letter strings were presented in the middle of the screen in 15-point Courier type, with $90 \%$ brightness set in the program. The distractor letter was presented $1.9^{\circ}$ above or below fixation, in 16-point Courier with brightness set to $100 \%$. Eighty English words (40 with three letters, 40 with eight letters) and 76 French words (38 with three letters, 38 with eight letters) were used for the English and French participants, respectively. Eighty nonwords and 76 nonwords (half of each with three letters, the other half with eight letters) were constructed from the English and French words, respectively, by changing each vowel to a consonant. The average frequencies were 116 and $55 \mathrm{oc}-$ currences per million, respectively, for the three- and eight-letter English words (according to the CELEX database) and 475 and 465 occurrences per million, respectively, for the three- and eight-letter French words (according to the BRULEX database).

Half of all letter strings included " $L$ " and did not include "S," and the other half included "S" and not "L." In order for the letter positions to be the same across three- and eight-letter strings, the threeletter strings were displayed at five different possible positions on a central row: aligned with the first letter of the eight-letter stimulus, with its second letter, and so forth. Three- and eight-letter strings subtended visual angles of $2.88^{\circ}$ and $7.68^{\circ}$, respectively.

Procedure. Each trial began with a $500-\mathrm{msec}$ presentation of a central fixation dot, followed by a $200-\mathrm{msec}$ display with the letter strings plus distractor. Participants used the keyboard and pressed " 1 " for target " $L$ " or " 3 " for target " $S$ " in the letter strings, as fast and accurately as possible, while ignoring the irrelevant distractor letter. Task response was followed with a 1,300-msec intertrial interval. Letter-string length and lexicality (word/nonword) were blocked. In each block, each of the 40 (or 38, in the French version) letter strings appeared twice: once in a compatible and once in an incompatible distractor condition. Trial order was random within a block. Each participant ran through eight blocks (two sets of the four different block types) of 80 (or 76 for the French participants) trials each for the English participants, preceded by a 10-trial training block. The 24 different orders of the four different block types were counterbalanced across the 24 participants in each language (so that each order was run twice, once on an English and once on a French participant).

\section{Results}

Participants with more than $15 \%$ errors or mean response times (RTs) over three $S D$ s from their group mean were removed from the analysis. This resulted in the exclusion of 4 English and 4 French participants (the latter were replaced by 4 new French participants). Incorrect responses and those faster than $250 \mathrm{msec}$ or slower than $1,800 \mathrm{msec}(1.2 \%$ of the overall data) were excluded from the RT analysis. Figure 1 shows the mean results. Within-subjects 2 (English or French) $\times 2$ (three or eight letters) $\times 2$ (words or nonwords) $\times 2$ (compatible or incompatible distractor) ANOVAs were conducted on the RTs and percentage errors, with participants $\left(F_{1}\right)$ and items $\left(F_{2}\right)$ as random factors.

RTs. The RT ANOVA revealed faster RTs for words than for nonwords $\left[F_{1}(1,43)=4.2, M S_{\mathrm{e}}=8,216, p<\right.$ $\left..05 ; F_{2}(1,304)=4.5, M S_{\mathrm{e}}=5,074, p<.05\right]$. This is a form of the word superiority effect (WSE; see, e.g., Allegretti \& Puglisi, 1982, for a similar WSE in search tasks). This effect interacted with language, however $\left[F_{1}(1,43)=\right.$ $10.2, M S_{\mathrm{e}}=8,216, p<.005 ; F_{2}(1,304)=24.2, M S_{\mathrm{e}}=$ $5,074, p<.001]$, so that the RT facilitation in words (vs. nonwords) was found for French but not for English. This may have been due to the lower frequency of the English words used. ${ }^{1}$

RTs were also faster for three-letter stimuli than for eight-letter stimuli $\left[F_{1}(1,43)=107.4, M S_{\mathrm{e}}=10,150, p<\right.$ $\left..001 ; F_{2}(1,304)=364.8, M S_{\mathrm{e}}=5,074, p<.001\right]$. This load effect also interacted with language $\left[F_{1}(1,43)=5.5\right.$, $M S_{\mathrm{e}}=10,150, p<.05 ; F_{2}(1,304)=3.7, M S_{\mathrm{e}}=5,074$, $p=.056]$. Load had a greater effect on RTs in French than in English.

More important for our present aim was the interaction between lexicality and load $\left[F_{1}(1,43)=4.6, M S_{\mathrm{e}}=5,303\right.$, $\left.p<.05 ; F_{2}(1,304)=7.7, M S_{\mathrm{e}}=5,074, p<.01\right]$, which indicated that the load effect was larger for nonwords than for words, as we expected. This effect of lexicality on load was not modulated by language $\left(F_{1}=1.6, p>.20 ; F_{2}<1\right)$.

RTs were faster in the compatible than in the incompatible distractor conditions $\left[F_{1}(1,43)=31.3, M S_{\mathrm{e}}=938\right.$, $\left.p<.001 ; F_{2}(1,156)=46.1, M S_{\mathrm{e}}=1,688, p<.001\right]$. This compatibility effect tended to be larger in English 

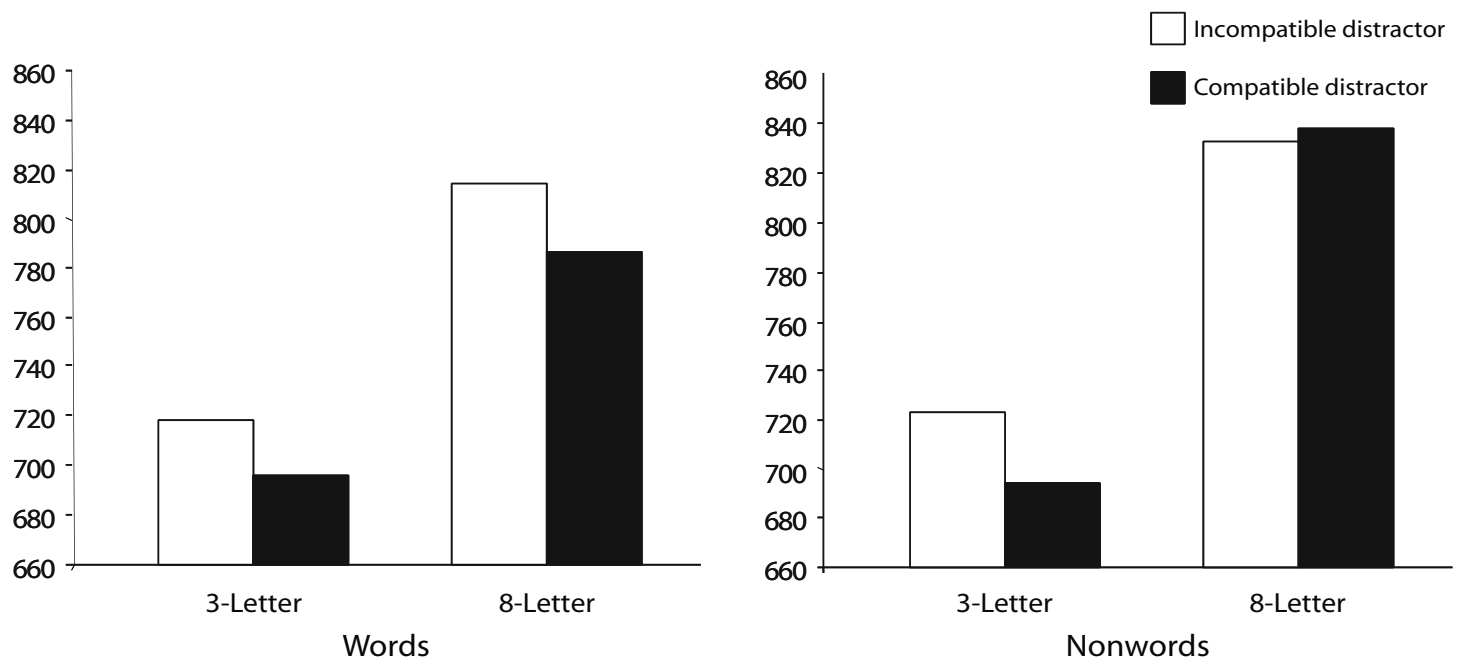

Figure 1. Mean response times (averaged across languages) as a function of length, lexicality, and distractor compatibility in Experiment 1.

than in French, but the interaction between language and compatibility was only significant in the items analysis $\left[F_{1}(1,43)=1.7, M S_{\mathrm{e}}=938, p=.19 ; F_{2}(1,304)=3.9\right.$, $\left.M S_{\mathrm{e}}=1,688, p<.05\right]$.

Distractor compatibility interacted with lexicality $\left[F_{1}(1,43)=5.8, M S_{\mathrm{e}}=565, p<.05 ; F_{2}(1,304)=3.7\right.$, $\left.M S_{\mathrm{e}}=1,688, p=.056\right]$. A greater distractor compatibility effect was found for words than for nonwords, as we predicted. Although there was a three-way interaction between lexicality, compatibility, and language in the participants ANOVA $\left[F_{1}(1,43)=4.7, M S_{\mathrm{e}}=565, p<.05\right]$, there was no such interaction in the items ANOVA $\left(F_{2}<1\right)$.

Most critical for our prediction was the interaction between lexicality, load, and distractor compatibility $\left[F_{1}(1,43)=11.7, M S_{\mathrm{e}}=708, p<.001 ; F_{2}(1,304)=6.2\right.$, $\left.M S_{\mathrm{e}}=1,688, p<.01\right]$, which was unaffected by language (i.e., $F_{1}, F_{2}<1$ for the four-way interaction). The pattern of this interaction was exactly as we predicted (see Figure 1). For nonwords, distractor compatibility effects at low load $(M=29 \mathrm{msec})$ were significantly reduced with high load $(M=-5 \mathrm{msec})\left[F_{1}(1,43)=12.29, M S_{\mathrm{e}}=\right.$ $1,046, p<.005 ; F_{2}(1,304)=8.5, M S_{\mathrm{e}}=1,688, p<$ $.001]$. In contrast, for words, there was no effect of load on distractor compatibility $\left(F_{1}, F_{2}<1\right)$, and the distractor compatibility effect was significant (all $F \mathrm{~s}>15, p \mathrm{~s}<$ $.01)$ for both three-letter $(M=22 \mathrm{msec})$ and eight-letter $(M=27 \mathrm{msec})$ words.

Errors. In replication of the RT results and previous findings of a WSE, the mean percentage errors were greater in the nonword $(M=7.4 \%)$ than in the word $(M=$ $3.9 \%)$ condition $\left[F_{1}(1,43)=23.6, p<.001 ; F_{2}(1,304)=\right.$ $35.5, p<.001]$. The load effect was also replicated in the error analysis, with a greater percentage of errors for eight-letter stimuli $(7 \%)$ than for three-letter stimuli $(4.2 \%)\left[F_{1}(1,43)=20.7, p<.001 ; F_{2}(1,304)=25.9, p<\right.$ $.001]$. Finally, as with the RTs, an interaction between lexicality and load $\left[F_{1}(1,43)=30.4, p<.001 ; F_{2}(1,304)=\right.$ $67.1, p<.001]$ indicated a greater effect of load for non- words (an increase of $5.8 \%$ on average with load) than for words (an increase of $0.2 \%$ with load). There were no other significant effects or interactions (all $p \mathrm{~s}>.10$ ).

\section{Discussion}

The present results provide support for our predictions that because of top-down facilitation of letter perception in words, the same increase in the number of letters would (1) lead to a smaller increase in perceptual load in words than in nonwords (this was supported by the finding that letter-string length produced a smaller increase in the RTs for words than for nonwords) and (2) only eliminate distractor perception (due to exhausting full perceptual capacity) in nonwords but not in words. The results showed that increasing the number of letters to a level that has been shown to exhaust capacity in previous studies (Lavie \& Cox, 1997) eliminated interference by an irrelevant distractor letter for the nonwords but not for the words. Thus, whereas three-letter strings are well within capacity for both words and nonwords, eight-letter strings only exhaust capacity for nonwords but not for words, in support of our predictions. ${ }^{2}$

\section{EXPERIMENT 2}

Experiment 2 was designed to address two issues. First, one might claim that the short exposure durations used in Experiment 1 (to preclude eye movements) may have led to performance being based at least to some extent on memory. ${ }^{3}$ The advantage found for words over nonwords may then at least in part have reflected a memory advantage. In Experiment 2, we therefore presented the task displays until response. Second, the blocked design in Experiment 1 is prone to alternative accounts in terms of different strategies used in the word versus nonword blocks or in low- versus high-load blocks. In Experiment 2, we therefore mixed all trial types in a block. Since perceptual load effects have already been found in such mixed-trial designs (Lavie \& 
Cox, 1997), we expected the load effects to replicate for the nonwords conditions in the present experiment. The critical question was whether we could replicate the effects of lexicality in this mixed-trials design with long exposure durations that ruled out alternative accounts in terms of strategy or memory for the lexicality effects.

\section{Method}

Participants. Twenty-six new native French students from the Université de Provence with normal or corrected-to-normal vision participated.

Stimuli and Procedure. The experiment was conducted on a PC using E-Prime software. The stimuli from the French version of Experiment 1 were used, but since 15-point Courier was unavailable in E-Prime, the letter strings were presented in 18-point Courier and the distractor letter in 20-point Courier.

The procedure was the same as that for the French participants in Experiment 1, except that the task displays remained on the screen until response. If no response was made within $1,800 \mathrm{msec}$, the display terminated (in order to encourage speeded responses). All letter strings were now presented in the middle of the screen, to encourage central fixation, and all trial types were intermixed at random.

\section{Results}

The same exclusion and RT trimming criteria as in Experiment 1 resulted in the exclusion of 5 participants from the analyses and $2.8 \%$ of the remaining participants from the RT data. ANOVAs on RTs and percentage errors as a function of lexicality, load, and compatibility with participants $\left(F_{1}\right)$ and items $\left(F_{2}\right)$ as random factors were conducted. Mean RTs and percentage errors are given in Table 1.

RTs. RTs were faster for words than for nonwords $\left[F_{1}(1,20)=103.2, M S_{\mathrm{e}}=450.5, p<.001 ; F_{2}(1,145)=\right.$ 22.6, $\left.M S_{\mathrm{e}}=3,031.3, p<.001\right]$, thus replicating the WSE in this experiment. RTs were also faster for three-letter than for eight-letter stimuli $\left[F_{1}(1,20)=339.1, M S_{\mathrm{e}}=\right.$ $2,367, p<.001 ; F_{2}(1,145)=443.7, M S_{\mathrm{e}}=3,031.3, p<$ $.001]$. As expected, the effect of load was modulated again by lexicality $\left[F_{1}(1,20)=26.1, M S_{\mathrm{e}}=809.7, p<.001\right.$; $\left.F_{2}(1,145)=10.3, M S_{\mathrm{e}}=3,031.3, p<.005\right]:$ The load effect was greater for nonwords than for words, as before.

Distractor compatibility had a main effect on RTs again $\left[F_{1}(1,20)=28.1, M S_{\mathrm{e}}=388.1, p<.001 ; F_{2}(1,145)=\right.$ $\left.12.6, M S_{\mathrm{e}}=1,413.5, p<.001\right]$, and there was no interaction between compatibility and load or lexicality (both $F \mathrm{~s}<1$ for the compatibility $\times$ load interaction; for the

Table 1

Mean Response Times (RTs, in Milliseconds) and Percentage Errors (\%E) As a Function of Length, Lexicality, and Distractor Compatibility (Comp) in Experiment 2

\begin{tabular}{|c|c|c|c|c|c|}
\hline & \multirow[b]{2}{*}{ Comp } & \multicolumn{2}{|c|}{3 Letters } & \multicolumn{2}{|c|}{8 Letters } \\
\hline & & RT & $\% \mathrm{E}$ & RT & $\% \mathrm{E}$ \\
\hline \multirow[t]{3}{*}{ Words } & I & 542 & 7.0 & 662 & 8.1 \\
\hline & $\mathrm{C}$ & 526 & 7.0 & 638 & 6.8 \\
\hline & $\mathrm{I}-\mathrm{C}$ & 16 & 0 & 24 & 1.3 \\
\hline \multirow[t]{3}{*}{ Nonwords } & I & 555 & 6.3 & 708 & 11.4 \\
\hline & C & 535 & 5.9 & 703 & 8.3 \\
\hline & $\mathrm{I}-\mathrm{C}$ & 20 & 0.4 & 5 & 3.1 \\
\hline
\end{tabular}

Note-I, incompatible distractor; C, compatible distractor. compatibility $\times$ lexicality interaction, $F_{1}<1 ; F_{2}(1,145)=$ $1.2, p=.26]$.

The critical result for our prediction was again the interaction between lexicality, load, and compatibility; this was significant in the participants analysis $\left[F_{1}(1,20)=4.8\right.$, $\left.M S_{\mathrm{e}}=377.5, p<.05\right]$ and approached significance in the items analysis $\left[F_{2}(1,145)=2.9, M S_{\mathrm{e}}=1,413.5, p=.08\right]$. The pattern of interaction was again exactly as predicted (Table 1). Whereas for nonwords distractor compatibility effects were reduced by load $\left[F_{1}(1,20)=4.1 M S_{\mathrm{e}}=\right.$ $\left.314.5, p<.05 ; F_{2}(1,145)=3.2, M S_{\mathrm{e}}=1,413.5, p=.06\right]$ (Table 1, right columns), for words there was no effect of length on distractor compatibility (both $F_{\mathrm{s}}<1$ ), and the distractor compatibility effects (Table 1 , left columns) were significant $(p<.001)$ at both lengths.

Errors. Mean percentage error was greater for eightletter stimuli $(8.6 \%)$ than for three-letter stimuli $(6.5 \%)$ $\left[F_{1}(1,20)=6.2, M S_{\mathrm{e}}=29.8, p<.05 ; F_{2}(1,145)=5.8\right.$, $\left.M S_{\mathrm{e}}=54, p<.05\right]$. This load effect was greater for nonwords $(3.7 \%$ increase by load) than for words $(0.5 \%$ increase by load) $\left[F_{1}(1,20)=4.9, M S_{\mathrm{e}}=23.6, p<.05\right]$, but this interaction only approached significance in the items analysis $\left[F_{2}(1,145)=2.9, M S_{\mathrm{e}}=54, p=.08\right]$. No other effect or interaction was significant (all $\left.F_{\mathrm{S}}<1\right){ }^{4}$

\section{GENERAL DISCUSSION}

The present results demonstrate that increasing perceptual load by increasing the number of letters in a lettersearch task reduces distractor processing only as long as the search letters do not form a meaningful word. The same increase in the number of search letters was found to eliminate distractor effects for nonwords but led to a smaller effect on the letter-search RTs for words, leaving the reader prone to distraction when processing words. This effect was found when all display types were intermixed at random (Experiment 2), and hence cannot be attributed to strategy. The effect also generalized across both brief display durations that were too short to allow saccadic eye movements (Experiment 1) and displays that remained until response, thus precluding alternative accounts in terms of lexicality effects on memory (Experiment 2). Instead, the results suggest that whereas eight-letter nonwords exhaust perceptual capacity, leaving none available for distractor processing, eight-letter words (due to the top-down facilitation of letter perception; e.g., Coltheart et al., 2001; McClelland \& Rumelhart, 1981) leave spare capacity that spills over to distractor perception.

These findings provide support for Lavie's perceptual load theory of attention from a new perceptual load manipulation that varied for the same number of stimuli, whether these produced more (nonwords) or less (words) demand on attention. Of particular importance, the findings demonstrate the consequences of practicing a particular skill for selective attention. Following extensive practice with words, skilled readers processed words in a more efficient manner that imposed little demand on attention. This in turn made the process, however, more prone to distraction. 
It is important to note that the present findings by no means imply that semantic activation of word meaning is automatic, merely that orthographic activation of letters in words imposes less load on perceptual capacity. Although word recognition models agree that letter activation in words involves feedback activation from word representations, this may not entail a full semantic representation for each word, to the same extent as that accessed during reading. In other words, although our findings that distractor effects differ for words and nonwords imply that some process of reading may have occurred, we have no evidence that word meaning was fully accessed in our task (cf. Stroop tasks).

Thus, the apparent contradiction between the implication from our findings that words were read to some extent, despite their being irrelevant to our letter-search task, and previous findings that Stroop effects from color words are diluted when participants focus on a letter in a word (see, e.g., Besner, 2001) can be explained by pointing to the possibility that our task did not involve extraction of the full semantic word meaning.

To conclude, our findings highlight an important consequence of word reading for selective attention: Because word reading facilitates letter perception, it also becomes more vulnerable to distraction.

\section{AUTHOR NOTE}

This research was supported by Individual European Community Marie Curie Fellowship HPMF-CT-2002-02092 to the first author, held in the lab of the second author, and a project grant from the Wellcome Trust to the second author. Correspondence relating to this article may be sent to M. Brand-D'Abrescia, Laboratoire Parole et Langage, Université de Provence, 29 av. Robert Schuman, 13621 Aix en Provence CEDEX 1, France (e-mail: muriele.brand@lpl.univ-aix.fr).

\section{REFERENCES}

Allegretti, C. L., \& Puglisi, J. T. (1982). Recognition of letters in words and nonwords. Journal of General Psychology, 107, 139-148.

BESNER, D. (2001). The myth of ballistic processing: Evidence from Stroop's paradigm. Psychonomic Bulletin \& Review, 8, 324-330.

Coltheart, M., Rastle, K., Perry, C., Langdon, R., \& Ziegler, J. C. (2001). DRC: A dual-route cascaded model of visual word recognition and reading aloud. Psychological Review, 108, 204-256.

Eriksen, B. A., \& EriKsen, C. W. (1974). Effects of noise letters upon the identification of a target letter in a nonsearch task. Perception \& Psychophysics, 16, 143-149.

FISHER, D. F. (1982). Limited-channel models of automatic detection: Capacity and scanning in visual search. Psychological Review, 89, 662-692.

Healy, A. F. (1994). Letter detection: A window to unitization and other cognitive processes. Psychonomic Bulletin \& Review, 1, 333-344.

LaBERge, D., \& SAMuels, S. J. (1974). Toward a theory of automatic information processing in reading. Cognitive Psychology, 6, 293-323.

LaVIE, N. (1995). Perceptual load as a necessary condition for selective attention. Journal of Experimental Psychology: Human Perception \& Performance, 21, 451-468.

LaVIE, N. (2000). Selective attention and cognitive control: Dissociating attentional functions through different types of load. In S. Monsell \&
J. Driver (Eds.), Control of cognitive processes: Attention and performance XVIII (pp. 175-194). Cambridge, MA: MIT Press.

Lavie, N. (2005). Distracted and confused? Selective attention under load. Trends in Cognitive Sciences, 9, 75-82.

Lavie, N., \& Cox, S. (1997). On the efficiency of visual selective attention: Efficient visual search leads to inefficient distractor rejection. Psychological Sciences, 8, 1-4.

LAvie, N., \& Fox, E. (2000). The role of perceptual load in negative priming. Journal of Experimental Psychology: Human Perception \& Performance, 26, 1038-1052.

Lavie, N., Hirst, A., De Fockert, J. W., \& Viding, E. (2004). Load theory of selective attention and cognitive control. Journal of Experimental Psychology: General, 133, 339-354.

Madrid, G. D., LAVIE, N., \& LAVIDOR, N. (2007, January). Asymmetrical perceptual load in lateralized word recognition. Paper presented at the meeting of the Experimental Psychology Society, London.

McClelland, J. L., \& Rumelhart, D. E. (1981). An interactive activation model of context effects in letter perception: Part 1. An account of basic findings. Psychological Review, 88, 375-407.

Pylyshyn, Z., Burkell, J., Fisher, B., \& Sears, C. (1994). Multiple parallel access in visual attention. Canadian Journal of Experimental Psychology, 48, 260-283.

ReICHER, G. M. (1969). Perceptual recognition as a function of meaningfulness of stimulus materials. Journal of Experimental Psychology, 81, 275-280.

Wheeler, D. D. (1970). Processes in word recognition. Cognitive Psychology, 1, 59-85.

Yantis, S., \& Jones, E. (1991). Mechanisms of attentional selection: Temporally modulated priority tags. Perception \& Psychophysics, 50, 166-178.

\section{NOTES}

1. Although the effect of word frequency on WSE has not been systematically assessed, the WSE has typically been established with very high-frequency words. Indeed, our task produced the WSE with English words as well as the same effect of increased distractor effects with words (vs. nonwords) in a study (Madrid, Lavie, \& Lavidor, 2007) that used far more frequent English words (with an average frequency of $1,449.19$ occurrences per million, versus 55 and 116 occurrences per million of the English words in the present study, according to the CELEX database).

2. These findings appear to suggest that perceptual load operates in a threshold manner, so that distractor processing is eliminated only when capacity limits are reached. Although longer letter strings slowed RTs in words too (not just in nonwords), the RT increase was significantly smaller for words than for nonwords (and may, at least in part, have been due to word length effects on postperceptual (e.g., phonological) processes rather than on perceptual load. As such, despite the RT increase, the processing of eight-letter words did not exhaust perceptual capacity, and the spare capacity spilled over to the distractor perception. More direct demonstration that the effects of perceptual load on distractor processing are not gradual, but rather depend on whether capacity limits are approached or not, was found in previous research (e.g., Lavie \& Cox, 1997) showing that gradual increases in search load produce a clear main effect (serial search slope), but have no effect on distractor processing as long as the search display involves five items or less.

3. We thank Jennifer Stolz for raising this possibility

4. Although some numerical trends for congruency effects in the error rates did not mirror the RT results, these were small and inconsistent between participants (statistically insignificant) or experiments, and hence did not appear to reflect any true effect.

(Manuscript received June 22, 2006; revision accepted for publication February 11, 2007.) 